\title{
Influence of Pyrolysis Parameters on the Performance of CMSM
}

\author{
Marta C. Campo, ${ }^{1}$ Tymen Visser, ${ }^{2}$ Kitty Nijmeijer, ${ }^{2}$ Matthias Wessling, ${ }^{2}$ \\ Fernão D. Magalhães, ${ }^{1}$ and Adélio M. Mendes ${ }^{1}$ \\ ${ }^{1}$ Laboratory of Process, Environment and Energy Engineering (LEPAE), Chemical Engineering Department, Faculty of Engineering, \\ University of Porto, 4200-465 Porto, Portugal \\ ${ }^{2}$ Membrane Technology Group (MTG), Faculty of Science and Technology, University of Twente, 7500 Enschede, The Netherlands
}

Correspondence should be addressed to Adélio M. Mendes, mendes@fe.up.pt

Received 1 October 2008; Revised 29 January 2009; Accepted 11 March 2009

Recommended by Eugénio C. Ferreira

\begin{abstract}
Carbon hollow fiber membranes have been prepared by pyrolysis of a P84/S-PEEK blend. Proximate analysis of the precursor was performed using thermogravimetry (TGA), and a carbon yield of approximately $40 \%$ can be obtained. This study aimed at understanding the influence of pyrolysis parameters-end temperature, quenching effect, and soaking time-on the membrane properties. Permeation experiments were performed with $\mathrm{N}_{2}, \mathrm{He}$, and $\mathrm{CO}_{2}$. Scanning electron microscopy (SEM) has been done for all carbon hollow fibers. The highest permeances were obtained for the membrane submitted to an end temperature of $750^{\circ} \mathrm{C}$ and the highest ideal selectivities for an end temperature of $700^{\circ} \mathrm{C}$. In both cases, the membranes were quenched to room temperature.
\end{abstract}

Copyright (c) 2009 Marta C. Campo et al. This is an open access article distributed under the Creative Commons Attribution License, which permits unrestricted use, distribution, and reproduction in any medium, provided the original work is properly cited.

\section{Introduction}

Carbon molecular sieve membranes (CMSMs), pioneered by Koresh and Soffer in the 80 s, are a very recent research topic in the area of gas separation. These inorganic materials present great advantages over polymeric membranes, since they have comparatively high permeabilities and selectivities, together with high thermal and chemical stability [1-4]. The main applications for this type of membranes are, among others, air separation, landfill gas recovery, olefin/paraffin separation, hydrogen recovery, and natural gas processing.

Carbon membranes are produced by pyrolysis of a polymeric precursor under an inert atmosphere $[1,3]$. The main precursors mentioned in literature are, among others, polyimide, polyfurfuryl alcohol polyacrylonitrile, phenolic resins, and cellulose [3]. The precursor material should have a high-carbon yield and be thermosetting [2]. To further improve the separation capacity of CMSM, some authors have functionalized the carbon matrix by adding metals with affinity towards one of the permeating species [5]. This strategy was followed by Barsema et al. [6, 7]. These authors used a blend of P84/AgS-PEEK to produce flat sheet carbon membranes and determined the influence of $\mathrm{Ag}$ on the membranes' separation performance. However, the influence of the pyrolysis end temperature, soaking time or cooling procedure was not assessed. In the present work, a P84/SPEEK blend is used for the first time as a hollow fiber precursor for preparing carbon membranes and to study the influence of some of the pyrolysis parameters on the final performance. The hollow fiber configuration provides higher mechanical stability than flat sheet membranes.

The preparation of CMSM should be directed towards the tailoring of the final carbonaceous micropore network. The influence of the pyrolysis parameters and complementary treatments used for producing the final carbon membranes should be studied in order to better suit a certain application $[1,8]$. Examples of these complementary treatments are pore closing by carbon vapor deposition using a carbon-containing source, or pore widening by activation under an oxidative atmosphere [3,9-11]. The temperature programs followed in the pyrolysis, the cooling steps and the gas atmosphere employed, are all important aspects that have to be studied and optimized according to the selected precursor, having in mind the final application. 
CMSMs have two major disadvantages that still have to be overcome: mechanical brittleness and aging effects $[4,12]$. Aging is caused by oxygen chemisorption on the carbon surface, which reduces the membrane performance due to reduction of pore size [12]. The presence of oxygenated functional groups on the surface of CMSM was reported by other authors [12-14]. The resulting adsorption of species with affinity to these oxygenated functional groups such as $\mathrm{CO}_{2}$ may also contribute to this fact [15]. When the feed mixture is humidified, the oxygen content on the carbon matrix may lead to the adsorption of water vapor, which may block the passage of other species [16]. In this work the use of P84/SPEEK hollow fibers is suggested for overcoming these problems. Evidences of aging effects will also be looked for in carbon membranes out of this precursor.

\section{Experimental}

2.1. Materials and Precursor Preparation. The precursor asymmetric hollow fiber membranes were prepared from a blend of $3.5 \mathrm{wt} \%$ S-PEEK and $96.5 \mathrm{wt} \%$ P84. P84 (BTDATDI/MDI) is a commercial available copolyimide from Lenzing, and S-PEEK is custom made polymer obtained by sulphonation of poly (ether ether ketone) (PEEK, Victrex). A few $\%$ of S-PEEK in the blend introduces additional hydrophilicity and may help suppressing macrovoids in spinning fibers. The P84/S-PEEK hollow fibers were obtained by the dry/wet phase separation process using spinning technology. For this purpose the dope used consisted of $71 \%$ of NMP (N-methyl-pyrrolidone, Merck 99\%), and 18\% P84/SPEEK blend. Additives were $6 \mathrm{wt} \%$ polyvinylpyrrolidone (PVP K90, Acros) and $5 \mathrm{wt} \%$ glycerol (Merck >99\%), and the coagulant medium was tap water. In order to induce pore formation on the inside and outside skin, a bore and shell liquid were used with, respectively, 80/20 and 90/10 wt $\%$ $\mathrm{NMP} / \mathrm{H}_{2} \mathrm{O}$. An air gap was used of $20 \mathrm{~mm}$, and the fibers were spun at room temperature. More details about the spinning process can be found elsewhere $[17,18]$.

2.2. Thermogravimetric Analysis of Precursor. The precursor used in this study was a copolyimide P84/S-PEEK blend. The thermogravimetric proximate analysis performed is a method developed by Ottaway [19] to determine the moisture, volatile matter, fixed carbon, and ash contents of a sample. The heating procedure consists on rising the temperature at $25^{\circ} \mathrm{C} \mathrm{min}$ min $^{-1}$ under nitrogen, with dwelling times at 50 and $110^{\circ} \mathrm{C}$ (10 and 7 minutes, respectively) and at $950^{\circ} \mathrm{C}$ ( 9 minutes under nitrogen plus 11 minutes under oxygen). After the second dwell at $110^{\circ} \mathrm{C}$, humidity is removed. Up to the third dwell, under nitrogen, volatile matter is released. Finally, after 11 minutes under oxygen at $950^{\circ} \mathrm{C}$, all the fixed carbon is lost, yielding ashes, if existent.

The proximate analysis of the precursor was performed in a Netzsch TG 209 F1 Iris thermogravimetric balance.

2.3. Fabrication of Carbon Hollow Fiber Membranes. The pyrolysis occurred inside a quartz tube installed in a Carbolite TZF 12/100 High Temperature Tubular Furnace

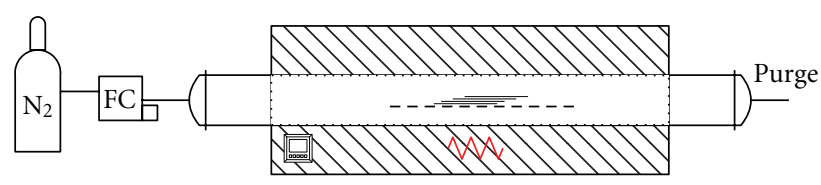

FIGURE 1: Scheme of the pyrolysis set-up.

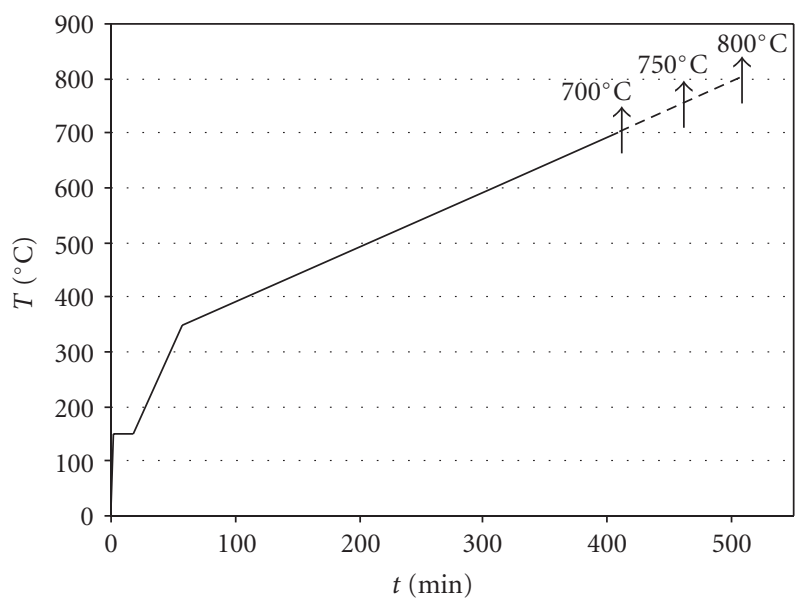

FIGURE 2: Heating procedure to prepare carbon membranes based in literature $[6,7]$.

with a Eurotherm $2408 \mathrm{CP}$ temperature controller, under a $50 \mathrm{ml}_{\mathrm{N}} \cdot \mathrm{min}^{-1}$ nitrogen atmosphere. The hollow fibers were supported on a stainless steel grid and introduced into the furnace with a cane as illustrated in Figure 1.

The temperature program employed is based on a program developed by Barsema et al. $[6,20]$ and shown in Figure 2. The membranes were heated from room temperature up to $150^{\circ} \mathrm{C}$ at $50^{\circ} \mathrm{C} \mathrm{min}{ }^{-1}$, remaining 15 minutes at this temperature. This step allowed the removal of any possible adsorbed water or residual solvents. Thereafter, the membranes were heated up to $350^{\circ} \mathrm{C}$ at $5^{\circ} \mathrm{C} \mathrm{min}^{-1}$. The heating rate up to the final temperature was then $1^{\circ} \mathrm{C} \mathrm{min}^{-1}$. This low heating rate prevents cracks from occurring during the formation of the carbon matrix. After achieving the maximum temperature of pyrolysis, here designated as end temperature, the membranes were submitted to quenching or to natural cooling. In some cases, they were kept at the end temperature for a certain time before cooling (soaking step). The main differences from Barsema's protocol relate to the end temperature, quenching procedure, and soaking time.

The quenching consisted on fast cooling inside a jacketed container, refrigerated with cold tap water, under nitrogen. "No" quenching means that the sole driving force for cooling was the temperature difference between the inside of the furnace and the surrounding room atmosphere. The transfer of the carbon hollow fibers from the furnace into the quenching container was performed as fast as possible, in order to minimize air exposure. Afterwards the membranes were stored in a box flushed with nitrogen.

The influence of a final step-soaking time-in which the oven end temperature was kept constant for 2 hours before quenching was also analysed. 
TABLE 1: Identification of the samples and pyrolysis' parameters.

\begin{tabular}{lccc}
\hline Sample & $T_{\text {END }}\left({ }^{\circ} \mathrm{C}\right)$ & Soaking time $(\mathrm{h})$ & Quenching \\
\hline HF-700-A & 700 & 0 & Yes \\
HF-700-B & 700 & 0 & No \\
HF-750-A & 750 & 0 & Yes \\
HF-750-B & 750 & 0 & No \\
HF-800-A & 800 & 0 & Yes \\
HF-800-B & 800 & 0 & No \\
HF-700-ST2h & 700 & 2 & Yes \\
\hline
\end{tabular}

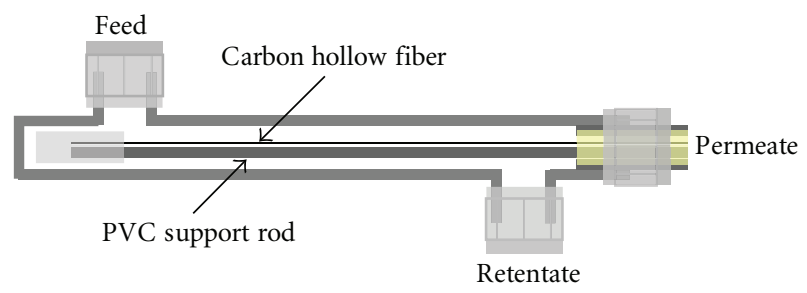

Figure 3: Scheme of the membrane module.

These two steps, soaking and quenching, may probably lead to microstructural rearrangements, affecting the pore size distribution and, consequently, the membrane selectivity.

Table 1 shows the identification of each carbon membrane prepared, concerning its pyrolysis' parameters.

2.4. Scanning Electron Microscopy. All samples identified in Table 1 were characterized by means of scanning electron microscopy using a JEOL JSM 5600 LV SEM; the fibers were fractured and the cross-sections analyzed. All the samples were previously sputtered with gold using a Balzers Union SCD 040 to allow better conductivity for SEM. Through the pictures taken it was possible to measure the thickness, $\ell$, of the selective layer located in the fiber bore side, the inner and outer diameters of each fiber, $D_{\text {in }}$ and $D_{\text {out }}$, and consequently the wall thickness, $\ell_{w}$. This information, together with the length of the carbon hollow fiber, $L$, allowed the calculation of the effective area of the selective layer of the membrane, $A_{m}$.

2.5. Permeation. After pyrolysis, the resulting carbon membranes were assembled in a module. Figure 3 illustrates the membrane module, where it is evidenced that feed circulates in the shell side, whereas permeate is removed from the bore side. These individual modules were then connected to a stainless steel housing which was introduced in a temperature controlled cabinet.

The permeation experiments were conducted at $30^{\circ} \mathrm{C}$, using a pressure increment method. The several carbon membranes were tested towards $\mathrm{N}_{2}, \mathrm{He}$, and $\mathrm{CO}_{2}$. All the modules were submitted to a 2 bar feed pressure on the shell side; whereas vacuum was applied on the bore side. Here, ideal gas behavior was assumed and, hence, the monocomponent permeance $P / \ell$ was calculated according to

$$
\frac{P}{\ell}=\frac{V_{P} v_{M}\left(p_{l}^{t}-p_{l}^{0}\right)}{\Re T t A_{m}\left(p_{h}-p_{l}\right)},
$$

where $V_{P}$ is the volume of the tank where the permeate is collected, $p_{l}$ and $p_{h}$ are, respectively, the permeate pressure and the feed pressure, $A_{m}$ is the effective area of the fiber, $T$ is the absolute temperature, $v_{M}$ is the molar volume of the gas, $\mathfrak{R}$ is the gas constant, and $t$ is the time. The ideal selectivity $\alpha_{i / j}$ for a certain pair of gases $i$ and $j$ is obtained from

$$
\alpha_{i / j}=\frac{P_{i}}{P_{j}}
$$

where $P_{i}$ and $P_{j}$ are the permeabilities of species $i$ and $j$, respectively.

\section{Results and Discussion}

3.1. Thermogravimetry. Proximate analysis is normally performed in order to determine the percentage of humidity, volatile matter, fixed carbon, and ashes [19]. The most important variable in this study is the yield of fixed carbon. This percentage accounts for the carbon content of the final carbon membrane. Higher fixed carbon content indicates that the resultant membranes have the potential to become more mechanically stable. Yields of fixed carbon are usually in the range of $25-50 \%$, depending on the precursor material [21]. Figure 4 presents the results of the proximate analysis. The normalized sample mass is represented as a function of time, and the heating procedure is referred to the secondary axis. The yield of fixed carbon is determined from the difference between the final mass and the mass at 63 minutes, being approximately $40 \%$. In the literature some polymers are reported to have carbon yields of almost 60\% [22]. However, the result of $40 \%$ for P84/S-PEEK blend can still be considered quite good. Probably due to the high P84 content in the blend, this value is similar to those reported in the literature for P84 alone [20,23].

It is known that S-PEEK and P84 have different thermal stabilities, but it is difficult to distinguish the precise contribution of each component for the shape of the thermogravimetric curve. Nevertheless, the first slope around $200^{\circ} \mathrm{C}$ should be caused by the degradation of the sulphonic acid group present in S-PEEK. Around $400^{\circ} \mathrm{C}$, a new slope is observed, due to the degradation of P84 [23]. Since the polymeric chain of S-PEEK decomposes at about $550^{\circ} \mathrm{C}$, this might be the cause for the final slope [24].

3.2. Scanning Electron Microscopy. SEM pictures were taken to compare the structures of the different samples. The pyrolysis operating variables, such as, end temperature, soaking time, and natural cooling procedure, have affected the dimensions of all studied fibers. Besides that, no other considerable changes are observed through SEM. Figure 5 provides an example of micrographs taken for sample HF 700B. This membrane was pyrolysed up to $700^{\circ} \mathrm{C}$ and 


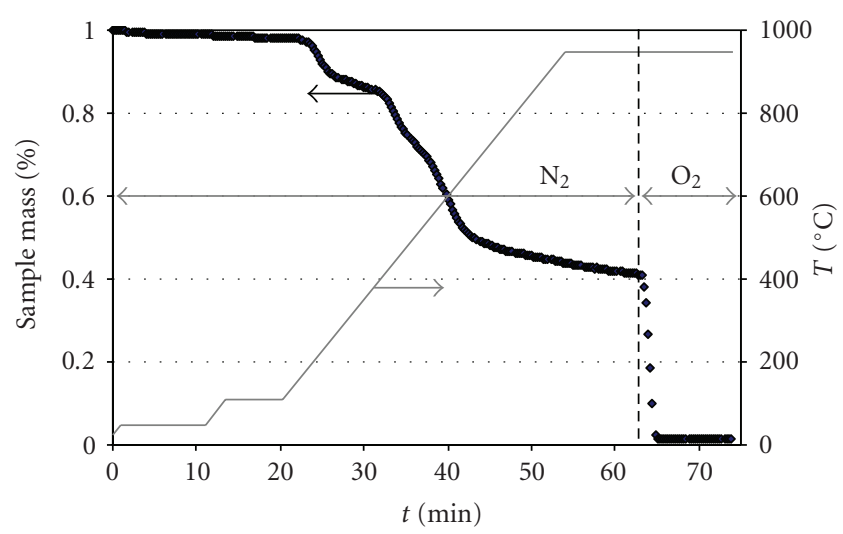

Figure 4: Typical sample mass and temperature histories during proximate analysis procedure.

naturally cooled. Table 2 summarized the dimensions of all carbon membranes studied.

It is seen that an increase in the pyrolysis end temperature originates a decrease of the inner and outer diameters of the fibers. This fact is sustained by the results of the proximate analysis, presented in Figure 4, which show that between 700 up to $800^{\circ} \mathrm{C}$ mass loss still occurs, as volatile matter is still being released. It is during this stage that heteroatoms are set free that the pore network is created. Also in Table 2, but regarding the $\mathrm{A} / \mathrm{B}$ pairs pyrolysed at the same end temperature but with different cooling procedures, it is noticeable that the nonquenched membranes have lower diameters. This may be related to higher mass loss and rearrangement of the carbon matrix occurring during the slow cooling. In agreement with these results, the membrane kept for 2 hours at $700^{\circ} \mathrm{C}$ before quenching (HF-700-ST2h) shows smaller dimensions than the one quenched with no soaking time (HF-700-A).

3.3. End Temperature Effect. The effect of the end temperature on the performance of carbon hollow fiber membranes can be studied by determining monocomponent permeances. Table 3 lists permeances and ideal selectivities for samples pyrolysed up to 700,750 , and $800^{\circ} \mathrm{C}$ towards $\mathrm{N}_{2}, \mathrm{He}$, and $\mathrm{CO}_{2}$. These results are plotted in Figure 6.

These results show that the membrane prepared with a $750^{\circ} \mathrm{C}$ end temperature displays the highest permeance towards all the species studied. For all the membranes, the species with lower permeance is $\mathrm{N}_{2}$, the species with larger size (Lennard-Jones kinetic diameter $0.364 \mathrm{~nm}$ ). On the other hand, $\mathrm{CO}_{2}$ has higher permeance than $\mathrm{He}$, despite its larger kinetic diameter $(0.33 \mathrm{~nm}$ and $0.26 \mathrm{~nm}$, resp.). However, it is known that $\mathrm{CO}_{2}$ has high adsorption affinity towards carbon matrixes, in opposition to $\mathrm{He}$, which mostly does not adsorb. It is being assumed that adsorption plays a significant role in the mass transport mechanism through these membranes: molecular sieving combined with activated diffusion.

The highest ideal selectivity values are achieved for an end temperature of $700^{\circ} \mathrm{C}$. The increase in permeances observed for all species when the temperature increases

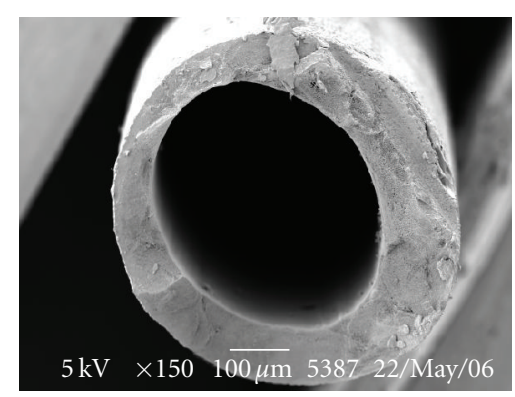

(a)

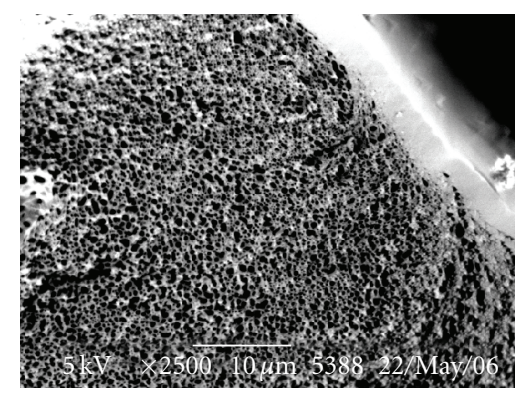

(b)

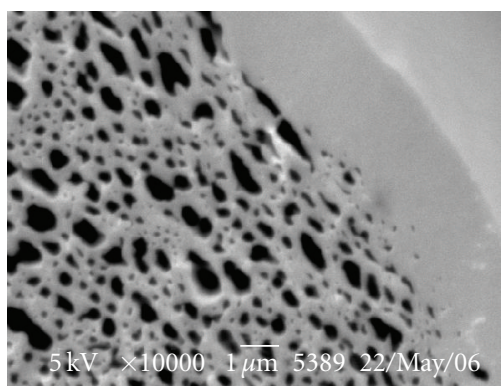

(c)

Figure 5: SEM pictures from HF-700-B carbon hollow fiber membrane cross-sections: (a) global view, $\times 150$ magnification, (b) inner view, $\times 2500$ magnification, and (c) inner view, $\times 10000$ magnification.

to $750^{\circ} \mathrm{C}$ might indicate that the total pore volume has increased, in the sense that more path ways are created enhancing the transport of the species. On the other hand, the decrease in selectivity for the pairs $\mathrm{CO}_{2} / \mathrm{N}_{2}$ and $\mathrm{He} / \mathrm{N}_{2}$ suggests that the mean pore width is also increasing, which impairs the sieving effect. At $800^{\circ} \mathrm{C}$ end temperature sintering mechanisms explain the decrease in permeances $[2,10,25]$.

3.4. Quenching Effect. In this study, as previously mentioned, it was intended to analyze the permeance dependency on the way membranes are cooled from the pyrolysis end temperature to room temperature. Table 4 summarizes the permeation data and ideal selectivities of the membranes obtained at different end temperatures from 700 up to $800^{\circ} \mathrm{C}$.

For each end temperature, the quenched membranes show larger permeances over the ones that were slowly cooled. This qualitatively indicates that the total pore volume 
TABLE 2: Characteristics of the carbon membranes.

\begin{tabular}{lcccccc}
\hline Sample & $D_{\text {in }}(\mu \mathrm{m})$ & $D_{\text {out }}(\mu \mathrm{m})$ & $\ell_{w}(\mu \mathrm{m})$ & $\ell(\mu \mathrm{m})$ & $L(\mathrm{~cm})$ & $A_{m}\left(\mathrm{~cm}^{2}\right)$ \\
\hline HF-700-A & 401 & 600 & 199 & 3.2 & 6.9 & 0.87 \\
HF-700-B & 397 & 588 & 190 & 3.1 & 6.4 & 0.80 \\
HF-750-A & 386 & 583 & 197 & 2.8 & 6.4 & 0.78 \\
HF-750-B & 387 & 570 & 183 & 2.8 & 7.5 & 0.91 \\
HF-800-A & 366 & 562 & 196 & 2.7 & 5.3 & 0.61 \\
HF-800-B & 356 & 536 & 180 & 2.9 & 6.3 & 0.70 \\
HF-700-ST2h & 397 & 585 & 188 & 2.8 & 5.4 & 0.67 \\
\hline
\end{tabular}

TABLE 3: Effect of end temperature on the permeance of carbon hollow fibers.

\begin{tabular}{lcccccc}
\hline & \multicolumn{2}{c}{ Permeance $\left(10^{-8} \times \mathrm{m}^{3} \mathrm{~N} \mathrm{~m}^{-2} \mathrm{kPa}^{-1} \mathrm{~s}^{-1}\right)$} & \multicolumn{3}{c}{ Ideal selectivity } \\
\hline Sample & $\mathrm{N}_{2}$ & $\mathrm{He}$ & 153 & $\mathrm{CO}_{2} / \mathrm{N}_{2}$ & $\mathrm{CO}_{2} / \mathrm{He}$ & $\mathrm{He} / \mathrm{N}_{2}$ \\
\hline HF-700-A & 9 & 107 & 416 & 18 & 1.5 & 12 \\
HF-750-A & 28 & 176 & 144 & 10 & 2.4 & 6.4 \\
HF-800-A & 14 & 97 & 1.5 & 7.0 \\
\hline
\end{tabular}

created during the heat treatment is maintained when the membrane is quenched. On the other hand, slow cooling allows for structural rearrangement of the carbon graphene layers, leading to pore narrowing. In the case of the carbon membranes prepared at $700^{\circ} \mathrm{C}$, the $\mathrm{He} / \mathrm{N}_{2}$ selectivity is higher for the naturally cooled membrane. Furthermore, the fact that the $\mathrm{CO}_{2} / \mathrm{He}$ selectivity turned smaller than unity indicates that the pore width has decreased together with the pore volume, revealing the onset of a molecular sieving effect towards $\mathrm{CO}_{2}$. It is also observed that the highest permeances are generically obtained when the membranes are quenched just after reaching $750^{\circ} \mathrm{C}$. For $750^{\circ} \mathrm{C}$, the quenching effect essentially affects the permeance and not the selectivities. Concerning the membranes prepared at $800^{\circ} \mathrm{C}$, the selectivities have decreased with quenching, except for the pair $\mathrm{He} / \mathrm{N}_{2}$. The pore volume and the pore width are disfavoring the permeation of the more adsorbed species, that is, $\mathrm{CO}_{2}$ and $\mathrm{N}_{2}$.

3.5. Soaking Time Effect. The soaking time consisted on keeping the membranes at the end temperature for a certain time interval, just before quenching. The effect of such a soaking time on the performance of carbon membranes is presented in Table 5.

In this case, from Table 5, all the permeances are enhanced by the existence of a final isothermal step at $700^{\circ} \mathrm{C}$ end temperature, but all the selectivities are lower. In fact, it can be seen in Figure 4 that mass loss is still occurring at this temperature. By keeping the membranes at $700^{\circ} \mathrm{C}$ for 2 hours, pores are enlarged, but this causes a decrease in selectivity. As expected, this decrease is more accentuated for pairs $\mathrm{CO}_{2} / \mathrm{N}_{2}$ and $\mathrm{He} / \mathrm{N}_{2}$, since the larger molecule $\mathrm{N}_{2}$ is more easily penetrating the pore network. Once again, higher permeances allied to lower selectivities might be an indication that the total pore volume has increased together with the mean pore width.

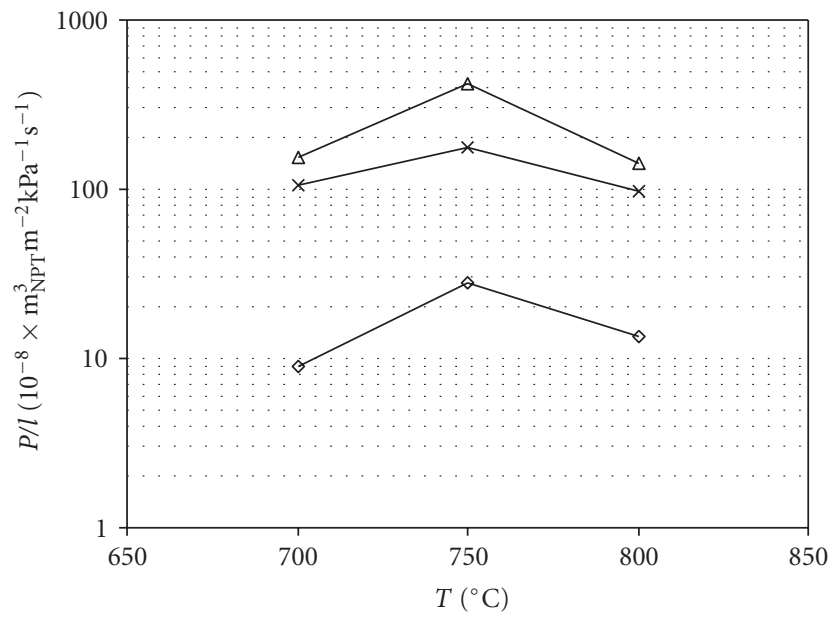

FIgURE 6: Permeation data of carbon membranes prepared up to 700,750 , and $800^{\circ} \mathrm{C}: \diamond-\mathrm{N}_{2}, \mathrm{x}-\mathrm{He}, \triangle-\mathrm{CO}_{2}$.

3.6. $\mathrm{CO}_{2}$ Exposure. After exposure to $\mathrm{CO}_{2}$, a check run was performed with $\mathrm{N}_{2}$ to assess any possible decrease in the membranes permeances. The presence of oxygenated functional groups on the surface of CMSM was reported by other authors [12-14], and the studies done in the scope of this work were to confirm the presence of such groups. $\mathrm{CO}_{2}$ is electron-deficient and thus acts as a Lewis-acid [15]. Although the membranes are essentially carbon, there may be some oxygenated groups on the surface [26], acting as a Lewis-bases and enhancing interactions with $\mathrm{CO}_{2}$. Hägg et al. [13] have shown that $\mathrm{CO}_{2}$ could plug pores leading to a decrease in permeances and suggested regeneration procedures at $200^{\circ} \mathrm{C}$ under inert atmosphere. Nevertheless, in the present work the experiments showed no loss in permeance due to $\mathrm{CO}_{2}$ exposure. The permeance of $\mathrm{N}_{2}$ after $\mathrm{CO}_{2}$ exposure matched the one obtained when the 
TABLE 4: Quenching effect on the permeance of carbon hollow fibers.

\begin{tabular}{|c|c|c|c|c|c|c|c|}
\hline \multirow[b]{2}{*}{ Sample } & \multirow[b]{2}{*}{ Quenching } & \multicolumn{3}{|c|}{ Permeance $\left(10^{-8} \times \mathrm{m}^{3}{ }_{\mathrm{N}} \mathrm{m}^{-2} \mathrm{kPa}^{-1} \mathrm{~s}^{-1}\right)$} & \multicolumn{3}{|c|}{ Ideal selectivity } \\
\hline & & $\mathrm{N}_{2}$ & $\mathrm{He}$ & $\mathrm{CO}_{2}$ & $\mathrm{CO}_{2} / \mathrm{N}_{2}$ & $\mathrm{CO}_{2} / \mathrm{He}$ & $\mathrm{He} / \mathrm{N}_{2}$ \\
\hline HF-700-A & Yes & 9 & 107 & 153 & 18 & 1.5 & 12 \\
\hline HF-700-B & No & 5 & 84 & 66 & 14 & 0.8 & 18 \\
\hline HF-750-A & Yes & 28 & 176 & 416 & 15 & 2.4 & 6.4 \\
\hline HF-750-B & No & 16 & 116 & 236 & 14 & 2.0 & 7.1 \\
\hline HF-800-A & Yes & 14 & 97 & 144 & 10 & 1.5 & 7.0 \\
\hline HF-800-B & No & 8 & 44 & 119 & 16 & 2.7 & 5.8 \\
\hline
\end{tabular}

TABLE 5: Effect of soaking time on the permeance of carbon hollow fibers.

\begin{tabular}{lcccccc}
\hline & \multicolumn{2}{c}{ Permeance $\left(10^{-8} \times \mathrm{m}^{3}{ }_{\mathrm{N}} \mathrm{m}^{-2} \mathrm{kPa}^{-1} \mathrm{~s}^{-1}\right)$} & \multicolumn{3}{c}{ Ideal selectivity } \\
\hline Sample & $\mathrm{N}_{2}$ & $\mathrm{He}$ & $\mathrm{CO}_{2}$ & $\mathrm{CO}_{2} / \mathrm{N}_{2}$ & 18 & $\mathrm{CO}_{2} / \mathrm{He}$ \\
\hline HF-700-A & 9 & 107 & 153 & 1.5 & 12 \\
HF-700-ST2h & 16 & 134 & 180 & 11 & 1.3 \\
\hline
\end{tabular}

membrane was virgin or fresh. This means that, if those oxygenated groups do exist in the carbon matrix, they do not interfere with the membrane's performance which means that carbon membranes done from this precursor have that advantage over the others.

\section{Conclusions}

The pyrolysis parameters studied in this paper influence the characteristics, and hence, the performance of the resulting carbon membranes out of P84/SPEEK. The highest permeances were obtained for the membranes submitted to an end temperature of $750^{\circ} \mathrm{C}$ and to quenching. The highest ideal selectivities were accomplished for the membrane submitted to $700^{\circ} \mathrm{C}$ and also to quenching. It was also concluded that the existence of a final soaking time, after reaching the end temperature, just before quenching, improved the permeance of the carbon membranes, but causes a decrease in selectivity. Furthermore, it was observed that the membranes quenched after reaching the end of the process revealed higher permeances than the ones naturally cooled. No decrease in the performance of the membrane due to $\mathrm{CO}_{2}$ exposure was observed.

\section{Acknowledgments}

The work of M. Campo was supported by FCT, Grant SFRH/BD/23833/2005. The authors would like to acknowledge the funding provided by FCT within research Project POCI/EQU/60246/2004.

\section{References}

[1] J. E. Koresh and A. Sofer, "Molecular sieve carbon permselective membrane-part I: presentation of a new device for gas mixture separation," Separation Science and Technology, vol. 18, no. 8, pp. 723-734, 1983.
[2] J. E. Koresh and A. Soffer, "Study of molecular sieve carbonspart 1: pore structure, gradual pore opening and mechanism of molecular sieving," Journal of the Chemical Society, Faraday Transactions 1, vol. 76, pp. 2457-2471, 1980.

[3] S. M. Saufi and A. F. Ismail, "Fabrication of carbon membranes for gas separation-a review," Carbon, vol. 42, no. 2, pp. 241-259, 2004.

[4] A. F. Ismail and L. I. B. David, "A review on the latest development of carbon membranes for gas separation," Journal of Membrane Science, vol. 193, no. 1, pp. 1-18, 2001.

[5] P. S. Tin, Y. Xiao, and T.-S. Chung, "Polyimide-carbonized membranes for gas separation: structural, composition, and morphological control of precursors," Separation and Purification Reviews, vol. 35, no. 4, pp. 285-318, 2006.

[6] J. N. Barsema, J. Balster, V. Jordan, N. F. A. van der Vegt, and M. Wessling, "Functionalized carbon molecular sieve membranes containing Ag-nanoclusters," Journal of Membrane Science, vol. 219, no. 1-2, pp. 47-57, 2003.

[7] J. N. Barsema, N. F. A. van der Vegt, G. H. Koops, and M. Wessling, "Ag-functionalized carbon molecular-sieve membranes based on polyelectrolyte/polyimide blend precursors," Advanced Functional Materials, vol. 15, no. 1, pp. 69-75, 2005.

[8] C. Liang, G. Sha, and S. Guo, "Carbon membrane for gas separation derived from coal tar pitch," Carbon, vol. 37, no. 9, pp. 1391-1397, 1999.

[9] A. F. Ismail and L. I. B. David, "Future direction of R\&D in carbon membranes for gas separation," Membrane Technology, vol. 2003, no. 4, pp. 4-8, 2003.

[10] A. Soffer, M. Azariah, A. Amar, et al., "Method for improving the selectivity of carbon membranes by carbon chemical vapor deposition," US Patent no. 5695818, 1997.

[11] A. Soffer, J. Gilron, S. Saguee, R. Hed-Ofek, and H. C. Topic, "Process for the production of hollow carbon fiber membranes," US Patent no. 5925591, 1999.

[12] I. Menendez and A. B. Fuertes, "Aging of carbon membranes under different environments," Carbon, vol. 39, no. 5, pp. 733$740,2001$.

[13] M.-B. Hägg, J. A. Lie, and A. Lindbråthen, "Carbon molecular sieve membranes: a promising alternative for selected industrial applications," Annals of the New York Academy of Sciences, vol. 984, pp. 329-345, 2003. 
[14] S. Lagorsse, F. D. Magalhães, and A. M. Mendes, "Aging study of carbon molecular sieve membranes," Journal of Membrane Science, vol. 310, no. 1-2, pp. 494-502, 2008.

[15] P. Raveendran, Y. Ikushima, and S. L. Wallen, "Polar attributes of supercritical carbon dioxide," Accounts of Chemical Research, vol. 38, no. 6, pp. 478-485, 2005.

[16] S. Lagorsse, M. C. Campo, F. D. Magalhãs, and A. M. Mendes, "Water adsorption on carbon molecular sieve membranes: experimental data and isotherm model," Carbon, vol. 43, no. 13, pp. 2769-2779, 2005.

[17] T. Visser, G. H. Koops, and M. Wessling, "On the subtle balance between competitive sorption and plasticization effects in asymmetric hollow fiber gas separation membranes," Journal of Membrane Science, vol. 252, no. 1-2, pp. 265-277, 2005.

[18] T. Visser, N. Masetto, and M. Wessling, "Materials dependence of mixed gas plasticization behavior in asymmetric membranes," Journal of Membrane Science, vol. 306, no. 1-2, pp. 16-28, 2007.

[19] M. Ottaway, "Use of thermogravimetry for proximate analysis of coals and cokes," Fuel, vol. 61, no. 8, pp. 713-716, 1982.

[20] J. Barsema, Carbon membranes: precursor, preparation, and functionalization, Ph.D. thesis, University of Twente, Enschede, The Netherlands, 2004.

[21] H. C. Foley, "Carbogenic molecular sieves: synthesis, properties and applications," Microporous Materials, vol. 4, no. 6, pp. 407-433, 1995.

[22] Y. Xiao, Y. Dai, T.-S. Chung, and M. D. Guiver, "Effects of brominating Matrimid polyimide on the physical and gas transport properties of derived carbon membranes," Macromolecules, vol. 38, no. 24, pp. 10042-10049, 2005.

[23] P. S. Tin, T.-S. Chung, Y. Liu, and R. Wang, "Separation of $\mathrm{CO}_{2} / \mathrm{CH}_{4}$ through carbon molecular sieve membranes derived from P84 polyimide," Carbon, vol. 42, no. 15, pp. 3123-3131, 2004.

[24] F. Celso, R. S. Mauler, and A. S. Gomes, "Estudo das propriedades térmicas de filmes poliméricos compostos de speek, derivados do benzoimidazol e ácido fosfotúngstico," Polímeros: Ciência e Tecnologi, vol. 18, no. 2, pp. 178-186, 2008.

[25] J. E. Koresh and A. Soffer, "The carbon molecular sieve membranes. General properties and the permeability of $\mathrm{CH}_{4} / \mathrm{H}_{2}$ mixture," Separation Science and Technology, vol. 22, no. 2-3, pp. 973-982, 1987.

[26] J. K. Brennan, T. J. Bandosz, K. T. Thomson, and K. E. Gubbins, "Water in porous carbons," Colloids and Surfaces A, vol. 187-188, pp. 539-568, 2001. 

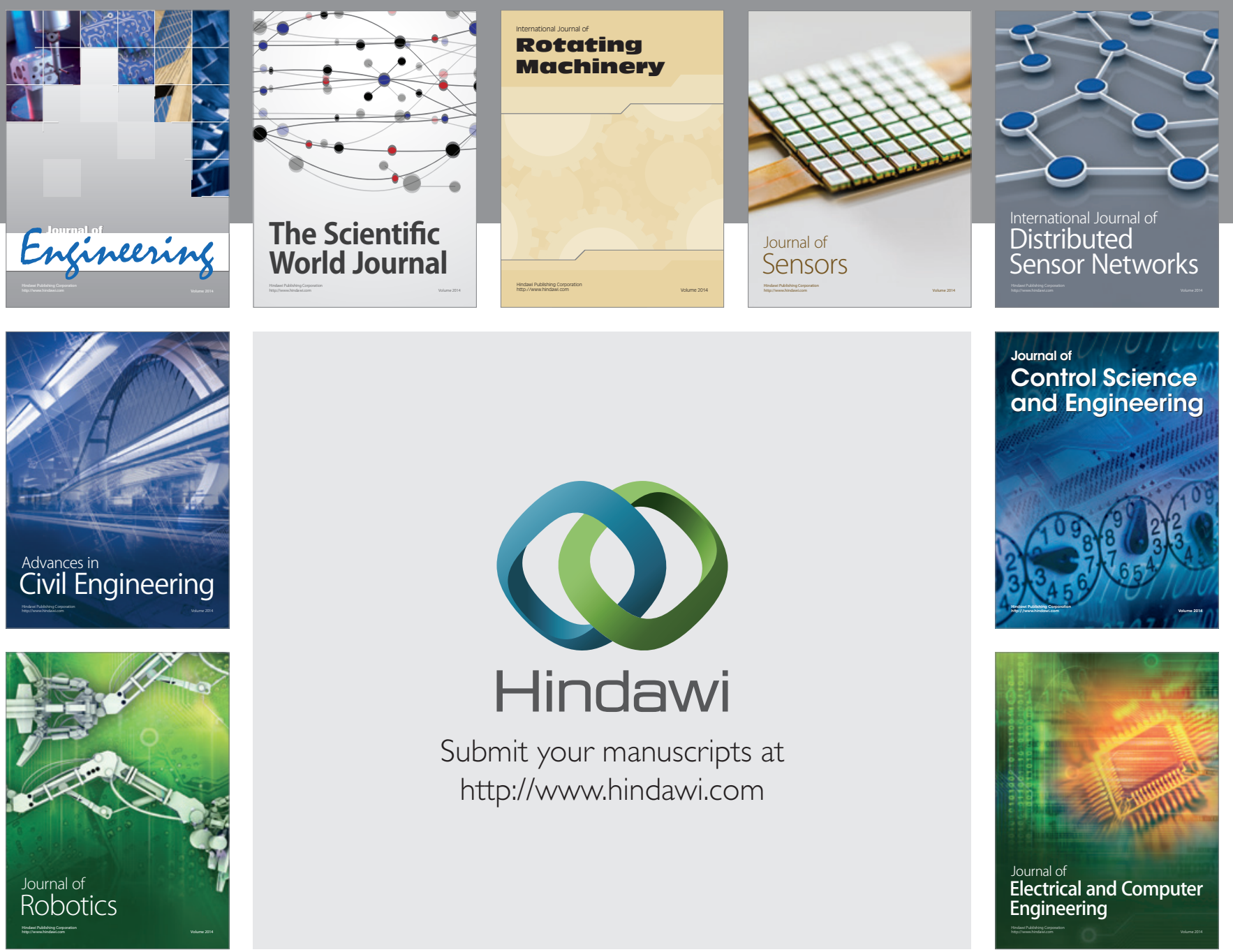

Submit your manuscripts at

http://www.hindawi.com
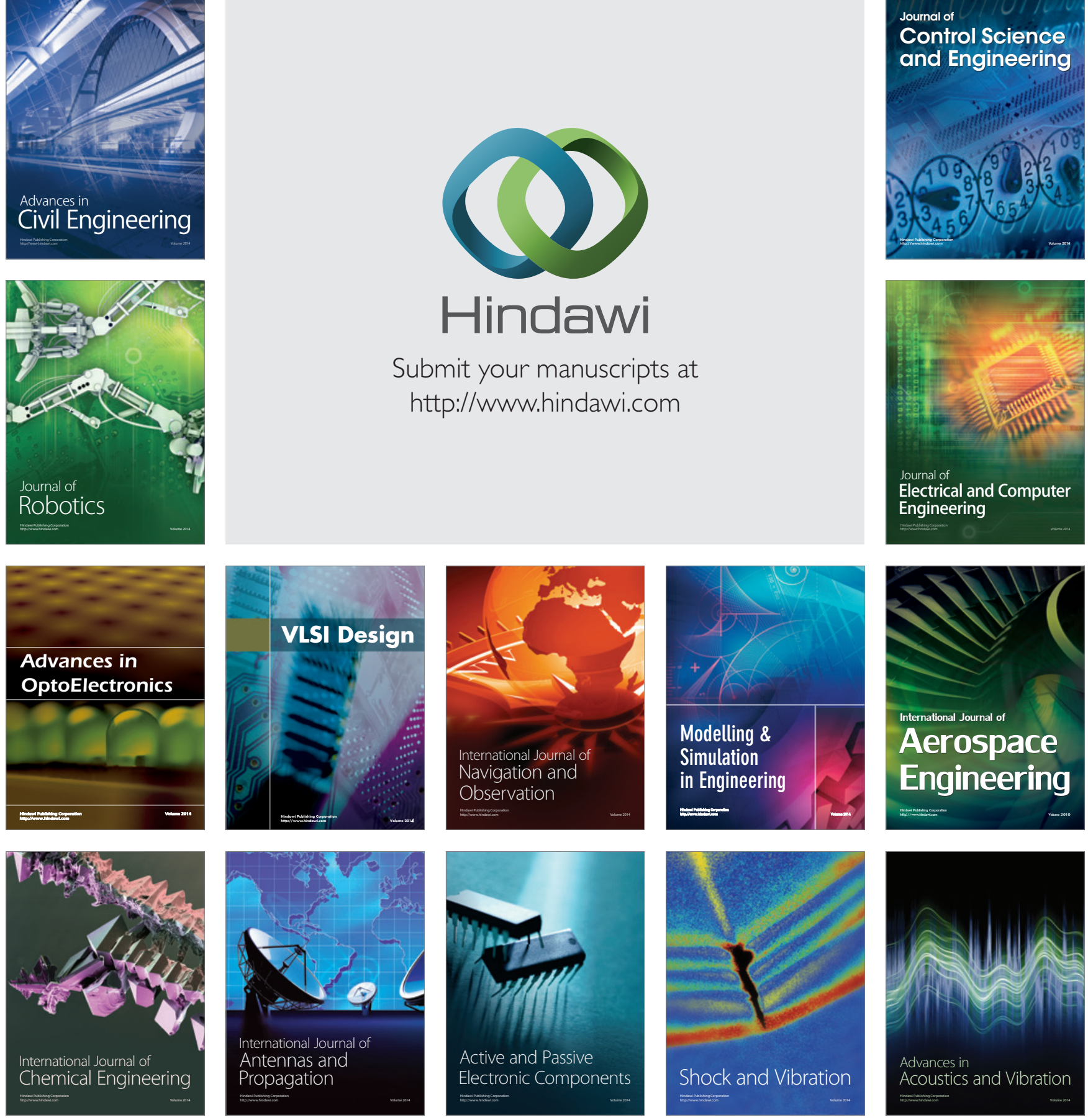